\title{
OPTIMAL CONTROLLABILITY OF IMPULSIVE CONTROL SYSTEMS
}

\author{
FARZANA A. MCRAE ${ }^{1}$ \\ Florida Institute of Technology \\ Department of Applied Mathematics \\ Melbourne, Florida 32901-6988 U.S.A.
}

\begin{abstract}
The problem of optimal controllability of a nonlinear impulsive control system is studied using the method of vector Lyapunov functions and the generalized comparison principle.
\end{abstract}

Key words: Impulsive control systems, optimal control, vector Lyapunov functions.

AMS (MOS) subject classifications: $\quad 34 \mathrm{~A} 37,49 \mathrm{~J} 15$.

\section{INTRODUCTION}

Many evolutionary processes are subject to short term perturbations which act instantaneously in the form of impulses. Thus impulsive differential equations provide a natural description of observed evolutionary processes of several real world processes [1].

Control theory is an area of application-oriented mathematics which deals with basic principles underlying the analysis and design of control systems [8]. A central problem in this area is the optimal control problem, that is, the problem of controlling a system in some "best" possible manner by minimizing some function of the trajectories.

In this paper, the problem of optimal controllability of a nonlinear impulsive control system is studied, using the method of vector Lyapunov functions and the generalized comparison principle $[3,4]$. An example is provided to illustrate the results.

\footnotetext{
${ }^{1}$ Received: March, 1993. Revised: May, 1993.
} 


\section{MAIN RESULTS}

We shall consider the following impulsive control system

$$
\left\{\begin{array}{cc}
x^{\prime}=f(t, x, u), & t \neq t_{k}, \quad k=1,2, \ldots \\
x\left(t_{k}^{+}\right)=x\left(t_{k}\right)+I_{k}(x, u), & k=1,2, \ldots \\
x\left(t_{0}\right)=x_{0} &
\end{array}\right.
$$

where $\quad 0<t_{1}<t_{2} \ldots<t_{k}<\ldots$ and $t_{k} \rightarrow \infty \quad$ as $\quad k \rightarrow \infty, \quad f \in P C\left[\mathbb{R}_{+} \times \mathbb{R}^{n} \times \mathbb{R}^{m}, \mathbb{R}^{n}\right]$, $I_{k} \in C\left[\mathbb{R}^{n} \times \mathbb{R}^{m}, \mathbb{R}^{n}\right]$ for every $k, k=1,2, \ldots$, and $u=u(t)$ is a control vector. Let $\Omega$ be the control prescribed. Corresponding to any control function $u=u(t)$, we shall denote a solution of $(2.1)$ by $x(t)=x\left(t ; t_{0}, x_{0}, u\right)$, with $x\left(t_{0}\right)=x_{0}$.

The following result deals with the optimal stabilization of (2.1).

Theorem 2.1: $\quad$ Assume that

(i) $0<\lambda<A$ are given,

(ii) $\quad V \in P C\left[\mathbb{R}_{+} \times \mathbb{R}^{n}, \mathbb{R}_{+}^{N}\right], V(t, x)$ is locally Lipschitzian in $x, Q \in \mathscr{G}\left[\mathbb{R}_{+}^{N}, \mathbb{R}_{+}\right]$, $g \in P C\left[\mathbb{R}_{+} \times \mathbb{R}_{+}^{N} \times \mathbb{R}^{n} \times \mathbb{R}^{m}, \mathbb{R}^{N}\right], g(t, w, x, u)$ is quasimonotone nondecreasing in $w$ and $\psi_{k}: \mathbb{R}_{+}^{N} \rightarrow \mathbb{R}^{N}$ is nondecreasing for $k=1,2, \ldots$,

(iii) $\Omega \subset \mathbb{R}^{m}$ is a convex, compact set and for $u^{0}(t) \in \Omega$, the system (2.1) admits unique solutions for $t \geq t_{0}$ and for $(t, x) \in \mathbb{R}_{+} \times S(A)$,

and

$$
b(\|x\|) \leq Q(V(t, x)) \leq a(\|x\|), a, b \in \mathscr{G}\left[\mathbb{R}_{+}, \mathbb{R}_{+}\right]
$$

$$
\left\|x+I_{k}(x)\right\|<\rho \text { whenever }\|x\|<A, \rho>A .
$$

(iv) $B\left[V, t, x, u^{0}, g\right] \equiv V_{t}(t, x)+V_{x}^{T}(t, x) f\left(t, x, u^{0}\right)+g\left(t, V(t, x), x, u^{0}\right) \leq 0, t \neq t_{k}$,

(v) $\quad C_{k}\left[V, t_{k}, x, \psi_{k}\right] \equiv \Delta V+\psi_{k}\left(V\left(t_{k}, x\left(t_{k}\right)\right)=0, k=1,2, \ldots\right.$, where $\Delta V=$ $V\left(t_{k}^{+}, x\left(t_{k}^{+}\right)\right)-V\left(t_{k}, x\left(t_{k}\right)\right)$,

(vi) $B[V, t, x, u, g] \geq 0$ for any $u \in \Omega, t \neq t_{k}$,

(vii) $a(\lambda)<b(A)$ holds,

(viii) any solution $w\left(t, t_{0}, w_{0}\right)$ of

$$
\left\{\begin{array}{cc}
w^{\prime}=-g\left(t, w, x^{0}(t), u^{0}(t)\right), & t \neq t_{k} \\
\Delta w=\psi_{k}\left(w\left(t_{k}\right)\right) & k=1,2, \ldots \\
w\left(t_{0}\right)=w_{0} \geq 0 &
\end{array}\right.
$$

exists on $\left[t_{0}, \infty\right)$ and satisfies 
and

$$
Q\left(w_{0}\right)<a(\lambda) \text { implies } Q\left(w\left(t, t_{0}, w_{0}\right)<b(A), t \geq t_{0}\right.
$$

$$
\lim _{t \rightarrow \infty} w\left(t ; t_{0}, w_{0}\right)=0
$$

Then, the control system (2.1) is practically asymptotically stable and the inequality

$$
\left\{\begin{array}{c}
\int_{t_{0}}^{\infty} g\left(s, V\left(s, x^{0}(s)\right), x^{0}(s), u^{0}(s)\right) d s+\sum_{k=1}^{\infty} \psi_{k}\left(V\left(t_{k}, x^{0}\left(t_{k}\right)\right)\right. \\
=\min _{u} \int_{t_{0}}^{\infty} g(s, V(s, x(s)), x(s), u(s)) d s+\sum_{k=1}^{\infty} \psi_{k}\left(V\left(t_{k}\right) x^{0}\left(t_{k}\right)\right) \\
\leq V\left(t_{0}, x_{0}\right) \text { holds. }
\end{array}\right.
$$

i.e. $u^{0} \in \Omega$ assures optimal stabilization.

Proof: To prove this theorem, we have to show two things:

(1) the control $u^{0}(t) \in \Omega$ assures practical asymptotic stability,

(2) the relation (2.5) holds.

Let $x^{0}(t)=x\left(t ; t_{0}, x_{0}, u^{0}\right)$ be the solution of (2.1) corresponding to the control $u^{0}(t) \in \Omega$. Then, setting $m(t)=V\left(t, x^{0}(t)\right), w_{0}=V\left(t_{0}, x_{0}\right)$ and using assumptions $(i)-(v)$, (vii) and (viii), we can prove that the system (2.1) is practically stable following the standard arguments of $[1,5,7]$. Then, we also have

$$
V\left(t, x^{0}(t)\right) \leq w\left(t ; t_{0}, w_{0}\right), t \geq t_{0} .
$$

Consequently, (2.4) implies that $\lim _{t \rightarrow \infty} x^{0}(t)=0$, which proves practical asymptotic stability.

Now, to prove (2.5), let us suppose that another control $u^{*}(t) \in \Omega$ also assures practical asymptotic stability of (2.1). Then, the corresponding solution $x^{*}(t)$ also satisfies $\left\|x^{*}(t)\right\|<A, t \geq t_{0}$, provided $\left\|x_{0}\right\|<\lambda$, and $\lim _{t \rightarrow \infty} x^{*}(t)=0$. This implies that

$$
\lim _{t \rightarrow \infty} V\left(t, x^{*}(t)\right)=0
$$

and we also have from $(2.6)$

$$
\lim _{t \rightarrow \infty} V\left(t, x^{0}(t)\right)=0
$$

Then, by (iv), we get

But by (2.7) and (vi), we get

$$
\left.\int_{t_{9}}^{\infty} g\left(s, V\left(s, x^{0} x\right)\right), x^{0}(s), u^{0}(s)\right) d s+\sum_{k=1}^{\infty} \psi_{k}\left(V\left(t_{k}, x^{0}\left(t_{k}\right)\right) \leq V\left(t_{0}, x_{0}\right) .\right.
$$




$$
\int_{t_{0}}^{\infty} g\left(s, V\left(s, x^{*}(s)\right), x^{*}(s), u^{*}(s)\right) d s+\sum_{k=1}^{\infty} \psi_{k}\left(V\left(t_{k}, x^{*}\left(t_{k}\right)\right) \geq V\left(t_{0}, x_{0}\right)\right.
$$

The inequalities (2.9) and (2.10) prove the desired relation (2.5) and the proof is complete.

Q.E.D.

The following simple example illustrates this result.

Example 2.1: $\quad$ Consider the following impulsive control system

$$
\left\{\begin{array}{cc}
x^{\prime}=F(t, x)+R(t, x) u & t \neq t_{k} \\
x\left(t_{k}^{+}\right)=b_{k} x_{k} & k=1,2, \ldots \\
x\left(t_{0}\right)=x_{0} &
\end{array}\right.
$$

where $F \in P C\left[\mathbb{R}_{+} \times \mathbb{R}^{n}, \mathbb{R}^{n}\right], R(t, x)$ is an $n \times m$ matrix and $u$ is a control.

We shall base the solution of the problem on the consideration of the function $V(t, x)$ given by

$$
V(t, x)=\sum_{i=1}^{N} a_{i} V_{i}(t, x), a_{i}=\text { const }>0
$$

where $V_{i}(t, v)$ are the components of Lyapunov's vector function.

Suppose we have

$$
V_{t}(t, x)+V_{x}^{T}(t, x) F(t, x) \equiv p(t, x) \leq \lambda^{\prime}(t) V(t, x)
$$

where $\lambda^{\prime}(t) \geq 0, t \geq t_{0}$ and $\lambda \in C^{1}\left[\mathbb{R}_{+}, \mathbb{R}_{+}\right]$.

Define, for $t \neq t_{k}$,

$$
B[V, t, x, u]=p(t, x)+V_{x}^{T} R(t, x) u+w(t, x)+u^{T} D u
$$

where $D$ is an $m \times m$ non-singular matrix.

We shall find the control $u^{0}=u^{0}(t) \in \Omega$ from the condition of the minimum of $B$ :

$$
\begin{aligned}
B[V, t, x, u] & =0 \text { at } u=u_{0} \\
\frac{\partial B}{\partial u}[V, t, x, u] & =0 \text { at } u=u_{0}
\end{aligned}
$$

Thus we obtain

$$
R^{T}(t, x) V_{x}(t, x)+2 D u^{0}=0
$$

and it then follows that 


$$
u^{0}(t)=-\frac{1}{2} D^{-1} R^{T}(t, x) V_{x}(t, x)
$$

To discuss the problem of minimization of $\left.\int_{0}^{\infty} g(s, V(s, x(s)), x(s)), u(s, x(s))\right) d s$, we obtain from (2.13), (2.14) and (2.16) the relation

$$
w(t, v)+p(t, x)-u^{0 T} D u^{0}=0
$$

which yields

$$
w(t, x)=-p(t, x)+u^{0 T} D u^{0}
$$

Thus

$$
\begin{gathered}
-g(t, v, x, u)=p(t, x)-u^{0 T} D u^{0}-u^{T} D u \\
\leq \lambda^{\prime}(t) V-u^{0 T} B u^{0}-u^{T} D u, t \neq t_{k^{*}}
\end{gathered}
$$

For $t=t_{k}$, we want

$$
V\left(t_{k}^{+}, x\left(t_{k}^{+}\right) \leq d_{k} V\left(t_{k}, x\left(t_{k}\right)\right)\right.
$$

where $\alpha d_{k} \leq e^{\lambda\left(t_{k}\right)-\lambda\left(t_{k+1}\right)}, \alpha>1$. Thus, $u^{0}=-\frac{1}{2} D^{-1} R^{T}(t, x) V_{x}(t, x)$ assures optimal stabilization of (2.1).

\section{REFERENCES}

[1] Bainov, D.D., Lakshmikantham, V., and Simeonov, P., Theory of Impulsive Differential Equations, World Scientific, Singapore 1989.

[2] Barnett, S. and Cameron, R.G., Introduction to Mathematical Control Theory, Oxford University Press, Oxford, England 1985.

[3] Lakshmikantham, V. and Leela, S., Differential and Integral Inequalities, Vol. I, Academic Press, New York 1969.

[4] Lakshmikantham, V., Matrosov, V.M. and Sivasundaram, S., Vector Lyapunov Functions and Stability Analysis of Nonlinear Systems, Kluwer Academic Publishers, The Netherlands 1991.

[5] Lakshmikantham, V., Leela, S., and Martynyuk, A.A., Practical Stability of Nonlinear Systems, World Scientific, Singapore 1990.

[6] Martynyuk, A.A., On practical stability and optimal stabilization of controlled motion, Math. Control Theory, Banach Center Publications 14, (1985), pp. 383-398.

[7] McRae, F.A., Practical stability of impulsive control systems, JMAA, to appear.

[8] Sontag, E.D., Mathematical Control Theory, Springer-Verlag, Berlin 1990. 


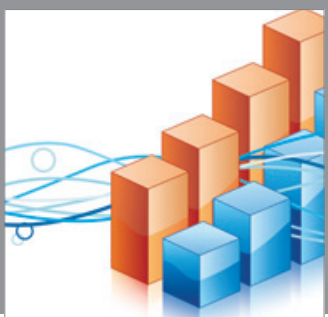

Advances in

Operations Research

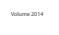

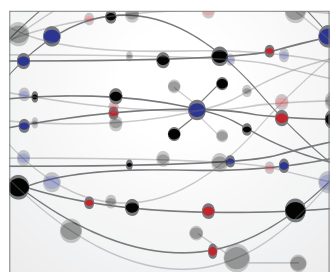

\section{The Scientific} World Journal
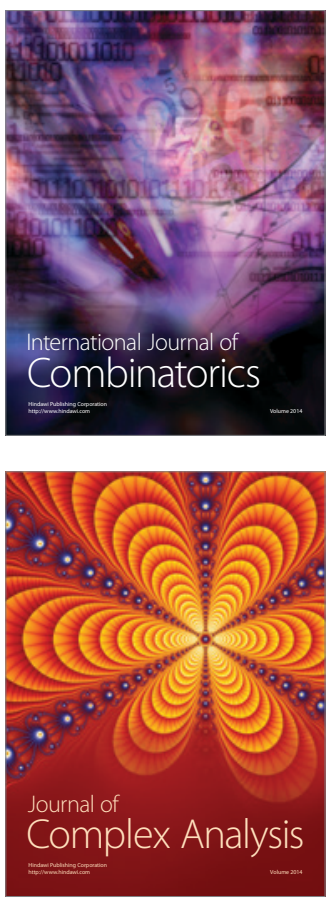

International Journal of

Mathematics and

Mathematical

Sciences
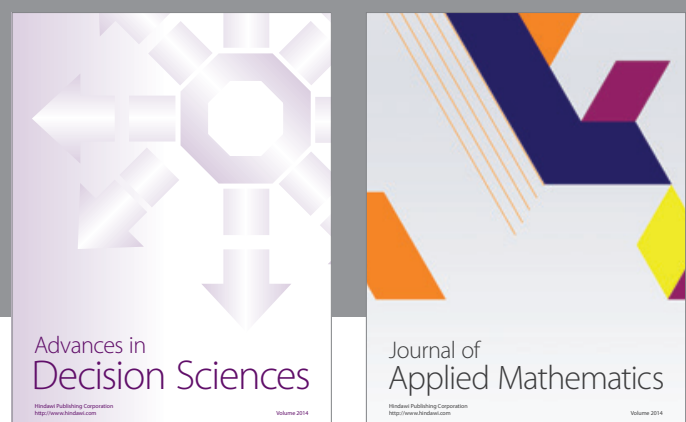

Journal of

Applied Mathematics
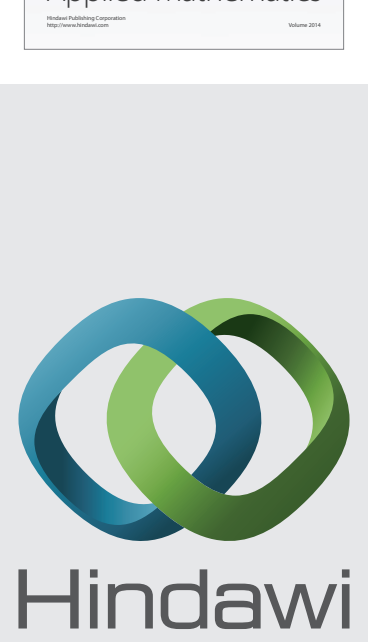

Submit your manuscripts at http://www.hindawi.com
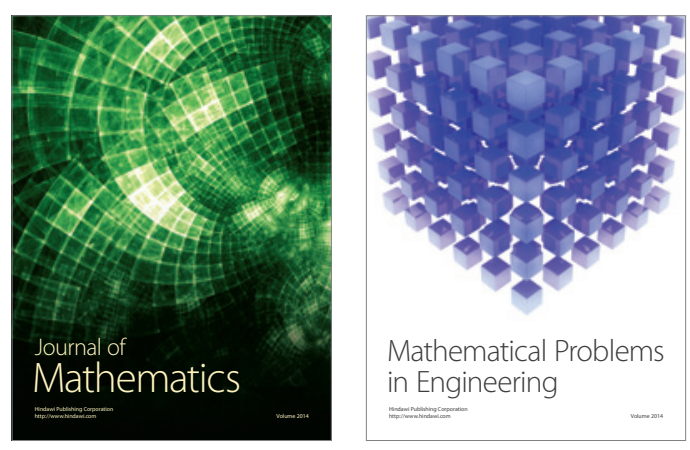

Mathematical Problems in Engineering
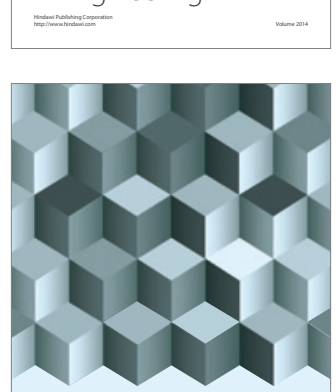

Journal of

Function Spaces
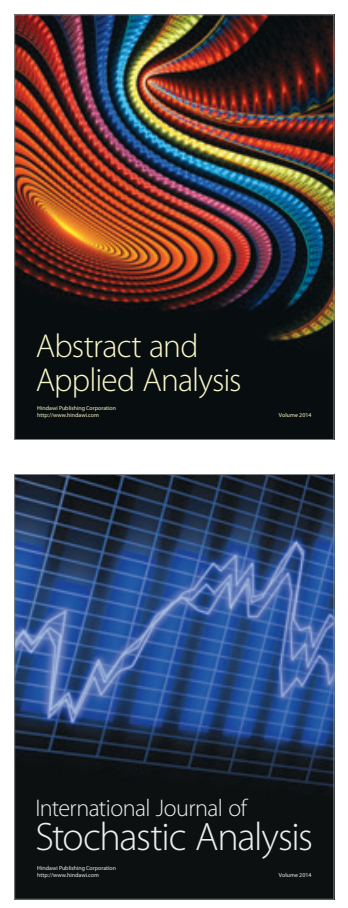

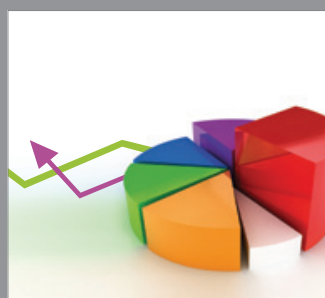

ournal of

Probability and Statistics

Promensencen
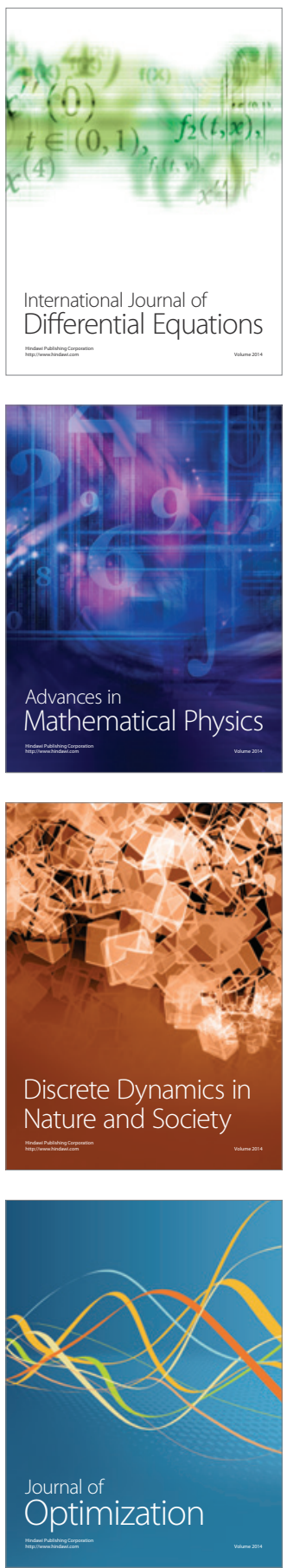